\title{
Does anxiety modify sexuality of pregnant women?
}

\author{
Iwona Gałązka, Agnieszka Drosdzol-Cop, Beata Naworska, \\ Mariola Czajkowska, Violetta Skrzypulec-Plinta \\ Medical University of Silesia, Katowice, Poland
}

\begin{abstract}
Objectives: The aim of this study was to evaluate the influence of anxiety on women's sexuality during pregnancy.

Material and methods: The prospective study involved 520 pregnant women at the age of 18-45. 168 of them were qualified for the final analysis. The research tools were: a self-designed questionnaire for women and standardized STAI scale.

Results: The state and trait anxiety in pregnant women was evaluated during all trimesters of pregnancy. State anxiety was stronger among women with a strong tendency to feelings of anxiety. The authors also tried to determine the correlation between women's assessment of their relationship with the partners and its impact on state and trait anxiety during all three trimesters of pregnancy. Self assessment of relations between partners had statistically significant impact on the increase in state anxiety $(p=0.04)$ in multiparous women, who reported impairment of their relations with the partner, and had statistically significant impact on the increase in the trait anxiety in primiparous women $(p=0.02)$ and multiparous $(p=0.05)$ women, who reported deterioration of partnership especially in the second trimester of their pregnancy. Lower anxiety level in the second trimester contributed to the increased sexual activity.
\end{abstract}

Conclusions: Anxiety level during pregnancy significantly affected the quality of sexual activity. Lower anxiety level in the second trimester contributed to the increased sexual activity.

Key words: anxiety, partner relations, pregnancy, sexual behaviors

Ginekologia Polska 2017; 88, 12: 662-669

\section{INTRODUCTION}

Human sexuality is the effect of continuous processes of identity development and psychosexual maturation on various stages of life [1, 2]. Pregnancy often evokes strong emotions and increases the level of stress and anxiety. This continuous stress is the reflection of opposite feelings experienced by pregnant women: happiness and fear, anticipation and feeling of uncertainty, faith and doubts, trust and disbelief [3].

Women's mental condition is clearly impacting their sexuality and the course of pregnancy [4]. In $1991 \mathrm{~J}$. Raphael-Leff proposed pregnancy division based not only on physiological changes but also on mental ones [5]. According to this concept the first stage of pregnancy ends when the woman starts feeling fetal movements, the second stage lasts until increased fear of childbirth occurs and the third is the moment of delivery. On the basis of research and clinical observations she described changes and psychological processes that take place at the specific stages of pregnancy [5].
First stage of pregnancy is about mental state: increased emotional sensitivity, mood changes, irritability, poor memory, impaired concentration and increased susceptibility to fatigue and drowsiness. Women can suffer emotional numbness and the lack of pregnancy-related emotions, which in turn may lead to sexual numbness or cause psychosomatic symptoms such as pain in the lower abdomen $[3,5]$.

In the second phase of pregnancy according to J. Raphael-Leff, the relations with the child should be prioritized. Women start feeling fetal movements and create images of her child in her head, which has more to do with fantasizing than reality. Woman keeps imaging herself as a mother. At this stage a change in relations with her partner also takes place. She expects more emotional support from her partner. This stage compared to the first one is characterized by the increased interest in sex and greater sexual needs. However, the awareness of being pregnant and feeling fetal movements may affect sexual behaviors and frequency of sexual intercourses $[3,5]$. 
The third stage is about preparing for the delivery. During this time concerns relating to childbirth, possible complications and intense pain are likely to grow. A reduced interest in sexual activity can be also observed. The final phase of this stage is mainly about waiting to meet the child and take on a new role of a mother [3,5].

Due to the insufficient knowledge about physiological and mental factors affecting sexual reactions of pregnant women the authors of the study attempted to evaluate the impact of anxiety level on their sexuality. Identifying causes, effects and forms of behaviors of pregnant women will help women better understand changes they experience during pregnancy and properly evaluate their sexuality.

\section{OBJECTIVES}

The aim of this study was to evaluate the influence of anxiety level on women's sexuality during all three trimesters of the pregnancy.

\section{MATERIAL AND METHODS Study population}

The prospective study involved 520 pregnant women between 18-45 years of age. Initially 520 pregnant women were qualified for the study. They completed questionnaires during first, second and third trimesters when attending doctor and birthing school.

After first trimester 424 completed questionnaires were collected (96 pregnant women gave up). After second trimester 123 pregnant women opted out. In the third trimester 127 respondents did not take part in the study. Some of the surveyed women did not offer any explanation or reason for giving up the participation in the study. In many cases questionnaires were only partially completed. Six women were excluded from the research due to the lack of sexual partner during pregnancy. In the end the research group numbered 168 pregnant women.

Inclusion criteria were: age of 18-45 years, normal pregnancy, fully completed questionnaires and informed consent for participation in the study. The following women were excluded from the study: women suffering from pregnancy complications such as low-lying placenta, cervical incompetence, intrauterine growth retardation (IUGR), gestational diabetes and pregnancy induced hypertension; and women suffering from systemic conditions such as cardiovascular diseases, diabetes, bronchial asthma and hypertension; women with multiple pregnancies and pregnancies after assisted reproductive technology and women with no sexual partners.

The study was approved by the Bioethics Committee of the Medical University of Silesia in Katowice, Poland. All participants provided written consent as approved by the local ethics committee.

\section{Research methods}

Research tools included a questionnaire to establish general characteristics of the study group, which included questions relating to: social and demographic aspects, obstetrical and gynecologic history, relationship with the partner, the duration of the relationship, partner's attractiveness, attractiveness of the subjects (women used the scale 1 - unattractive, 10 - very attractive), the overall number of sexual partners, the frequency of sexual intercourses in all three trimesters of pregnancy, libido as compared to libido before the pregnancy and the evaluation of anxiety impact on women's sexuality in all three trimesters of pregnancy (self-assessment CD Spielberg's questionnaire STAI (STAI, State-Trait Anxiety Inventory), which is intended for the evaluation of state anxiety [STAI-x1] and trade anxiety [STAI-x2].

STAI questionnaire contains 40 statements altogether, divided into two parts. In the first section of the questionnaire (questions 1-20) the subjects evaluate their anxiety reactions as per their current state. They evaluate the level of anxiety they were aware of at the time of completing the questionnaire. The second section (questions 21-40) contains questions relating to their disposition to experiencing anxiety, hypothetical force organizing anxiety reactions of an individual. The subjects of the study were to select from 20 short statements the one which best reflected their feelings. The scores of the study were between $2-$ and 80 points and the higher the score, the stronger the anxiety (mild anxiety - no anxiety: 20-40 raw scores; moderate anxiety: 41-60 raw scores; severe anxiety: $61-80$ raw scores) [6]. Substantial analysis of data obtained by means of STAI questionnaire was carried out in cooperation with a psychologist.

\section{Statistical analysis}

For statistical analysis Excel 2001 and STATISTICA 9.1 were used. $P<0.05$ was assumed as the level of statistical significance. For statistical comparison of the results the following tests were used: Shapiro-Wilk test, Friedman test, Wilcoxon matched-pairs test, Kruskal-Wallis test, Mann-Whitney U test, Spearman's test, Kendall test, Fisher's exact test, Mc Nemar's test, Cochran's Q test.

\section{RESULTS}

\section{General characteristics of the study population}

The mean age of surveyed women was 27,8 $\pm 4,7$ years. The mean duration of surveyed women's partnership was $6,5 \pm 4,1$ years. The mean age of surveyed women's first sexual intercourse was $18,8 \pm 2,6$ years (Tab. 1). Most of the respondents came from cities with a population between $100.000-499.000$ (58.3\%). Almost half of them (45.8\%) had higher education qualifications. $86.9 \%$ of the women claimed to have housing conditions ensuring privacy and 
Table 1. Characteristics of the studied group

\begin{tabular}{|l|c|c|c|c|c|}
\hline Characteristic & Mean & Standard deviation & Median & $\mathbf{5}^{\text {th }}$ percentile & $\mathbf{9 5}^{\text {th }}$ percentile \\
\hline Age (years) & 27.8 & 4.7 & 28.0 & 20.0 & 35.0 \\
\hline The duration of partnership (years) & 6.5 & 4.1 & 6.0 & 1.5 & 13.5 \\
\hline First sexual intercourse (age) & 18.8 & 2.6 & 18.0 & 16.0 & 24.0 \\
\hline
\end{tabular}

intimacy. Professional activity of pregnant women participating in the study was also analyzed. $46.6 \%$ of them were white-collar workers, $25.6 \%$ of them were blue-collar workers and $27.8 \%$ were unemployed.

It was their first pregnancy for $56.5 \%$ of the women, their second pregnancy for $29.2 \%$, their third for $11.9 \%$, their fourth for $1.2 \%$ and their fifth for $1.2 \%$ of women. Studied population included women who had 1 miscarriage (8.3\%) and 2 miscarriages (2.4\%). Most of the women (89.3\%) did not report any miscarriages. Most of the women (97.6\%) had childbirth at full term. Preterm birth occurred in $2.4 \%$ of studied women.

\section{The assessment of anxiety}

When analyzing state and trait anxiety levels, pregnant women were divided into primiparous and multiparous. In multiparous women state anxiety did change over the three trimesters in a statistically significant way $(p=0.03)$. State anxiety decreased between first and second trimester from median $41.0(28.6 ; 52.4)$ to median 39.0 (24.0; 52.0) State anxiety increased between the second and third trimester from median $39.0(24.0 ; 52.0)$ to median $40.0(27.0 ; 54.7)$ in multiparous women (Fig. 1).

Trait anxiety levels did not change throughout three trimesters of pregnancy in primiparous or multiparous

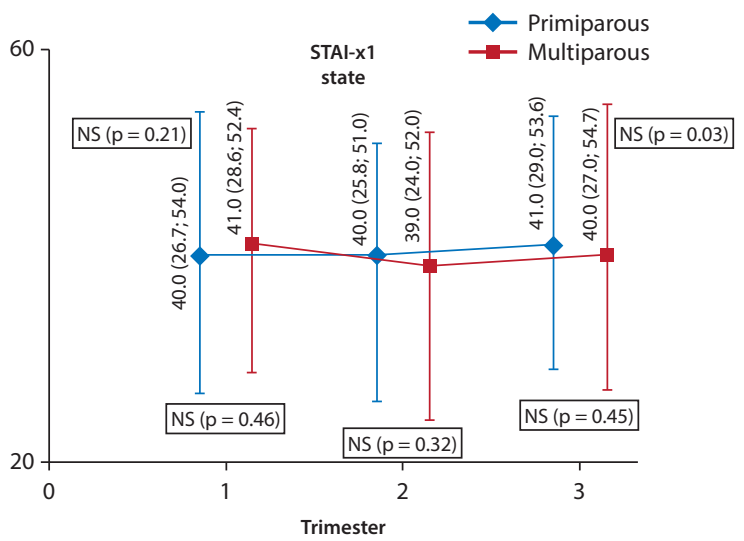

Figure 1. Levels of anxiety according to STAI-x 1 depending on the trimester of pregnancy in primiparous and multiparous women with the results of Mann-Whitney $U$ test for comparison of these groups in specific trimesters and Friedman test for a significant change in specific groups over the three trimesters. For descriptive statistics a median was used as a metric $\left(5^{\text {th }}\right.$ and $95^{\text {th }}$ percentile) women. They were not statistically different for specific trimesters either (Fig. 2).

The analysis of the state anxiety (Fig. 3) and trait anxiety (Fig. 4) in primiparous and multiparous women against the results of the comparison of these groups in specific trimesters of pregnancy and between these groups showed that changes in the level of state anxiety (Fig. 3) were statistically different for primiparous $(p=0.03)$ and multiparous ( $p=0.05$ ) women throughout three trimesters of pregnan$c y$. The difference between primiparas and multiparas for the first semester was not statistically significant $(p=0.06)$ and similar tendency was observed in the third semester $(p=0.07)$.

Both in the first and third trimester of pregnancy most of the primiparous women (52.6\%) had a low anxiety level while most of the multiparous women at the same stage had increased anxiety level (first trimester $57.5 \%$, third trimester $52.0 \%)$. In the second trimester in both primiparous (63.1\%) and multiparous women (57.5\%) low state anxiety prevailed. However, it should be noted that the highest percentage of women with a high anxiety level is observed among primiparas (first trimester 3.2\%, third trimester $4.2 \%$ ).

As for the trait anxiety (Fig. 4) statistically significant changes throughout three trimesters of pregnancy were observed only for primiparous women $(p=0.006)$ and no

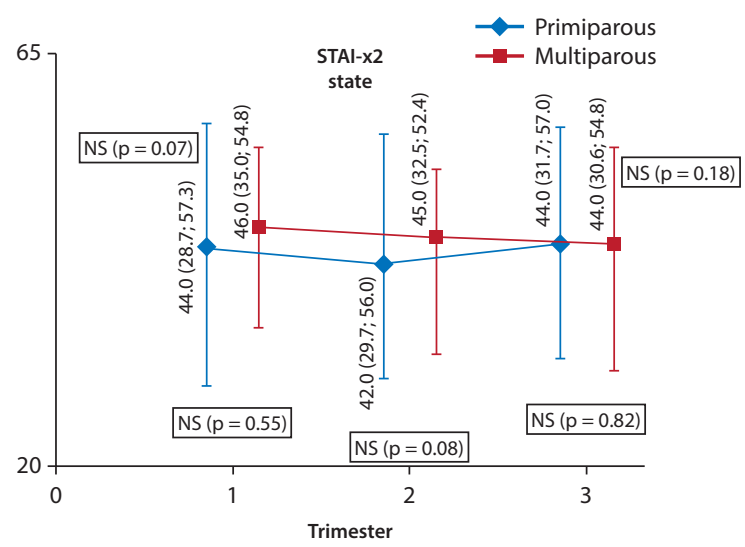

Figure 2. Levels of anxiety according to STAI-x2 depending on the trimester of pregnancy in primiparous and multiparous women with the results of Mann-Whitney $U$ test for comparison of these groups in specific trimesters and Friedman test for a significant change in specific groups over the three trimesters. For descriptive statistics a median was used as a metric ( $5^{\text {th }}$ and $95^{\text {th }}$ percentile) 


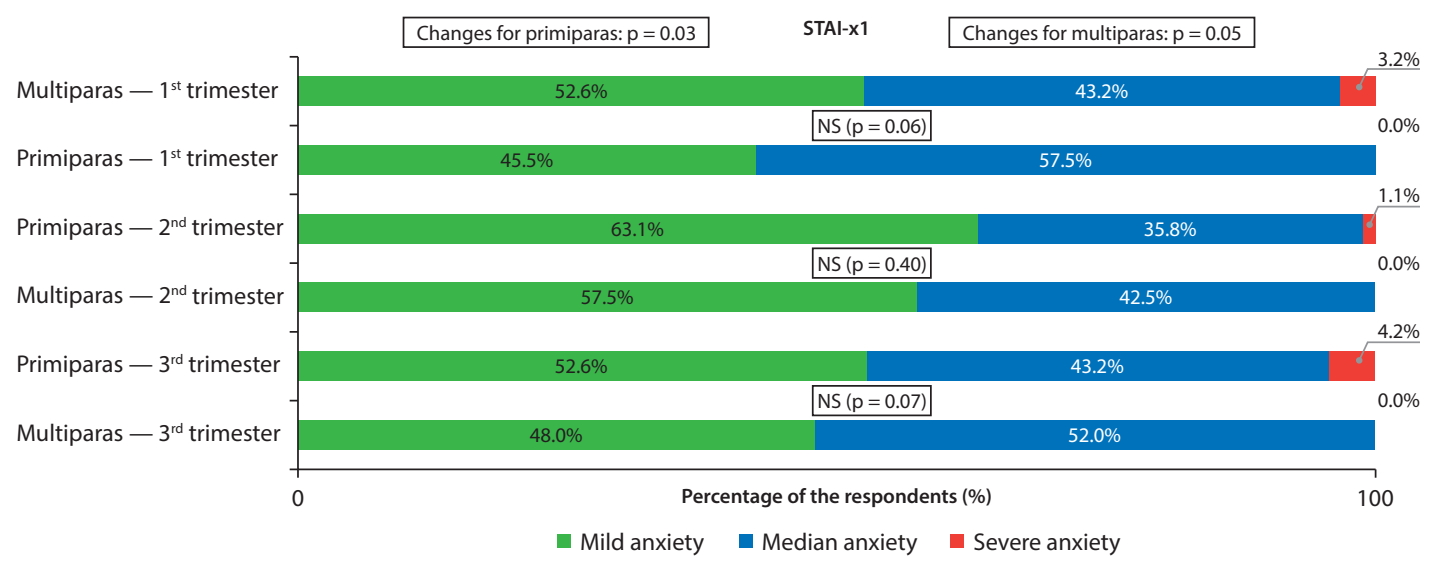

Figure 3. The distribution of anxiety levels according to STAI-x 1 depending on the trimester of pregnancy in primiparous and multiparous women with the results of the test for comparison of these groups in specific trimesters and test for a significant change in specific groups over the three trimesters

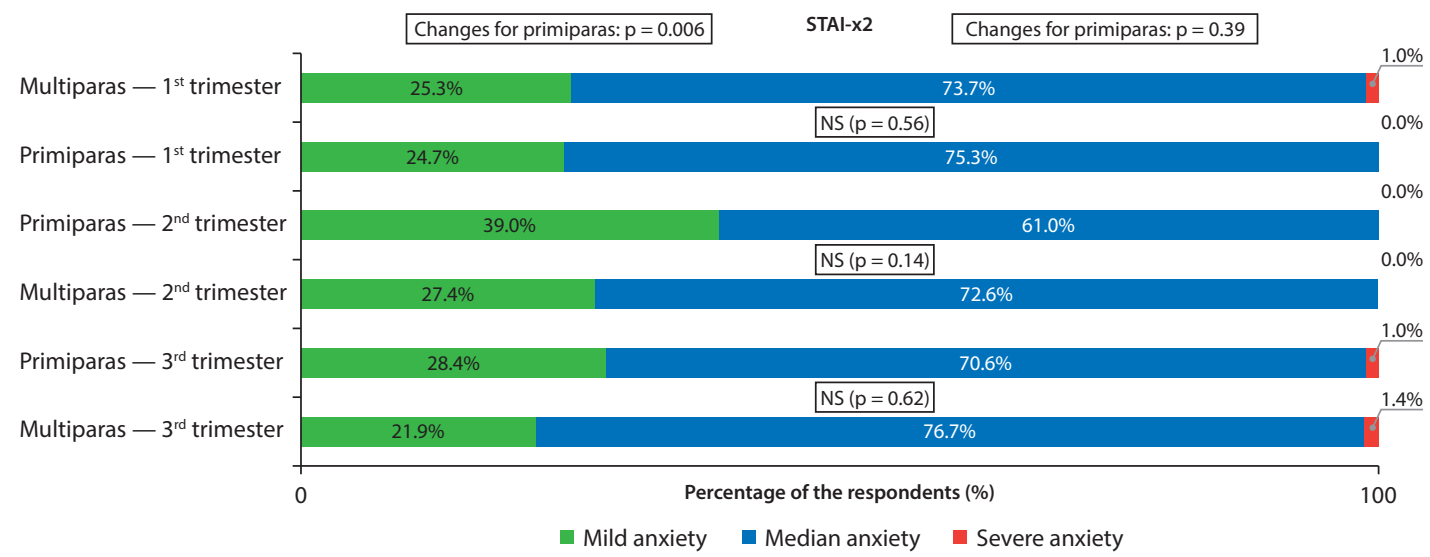

Figure 4. Levels of anxiety according to STAI-x2 depending on the trimester of pregnancy in primiparas and multiparas with the results of the test for comparison of these groups in specific trimesters and test for a significant change in specific groups over the three trimesters

statistical significance was observed between two groups in any of the trimester.

In both primiparous and multiparous women an increased anxiety could be observed (the difference is not statistically significant) during all three trimesers. The percentage of women ranged from $61.0 \%$ (second trimester) to $76.7 \%$ (third trimester). It should be noted that high anxiety was observed only in $1.0 \%$ of primiparous women in their first trimester, and in $1.0 \%$ of primiparous and 1.4 of multiparous women women in their third trimester of pregnancy.

The percentage of women with low anxiety level increased in primiparous (39.0\%) women in the second trimester of pregnancy (the difference is not statistically significant) (Figs. 3 and 4).

The impact of economic conditions on the level of state and trait anxiety was also investigated. Kruskal-Wallis test did not reveal any statistically significant impact on this variable on the anxiety level of the subjects (Tab. 2).
Everyday stress had impact on the state anxiety $(p=0.02)$ only in the first trimester of pregnancy. However, it did not affect trait anxiety in any trimester. The research did not show a statistically significant impact of this variable on the state or trait anxiety in the course of pregnancy. The impact of age and education on the level of anxiety in pregnant women was also assessed. No statistically significant relationship between subjects' age and education and the level of state and trait anxiety was revealed.

\section{Self-assessment of partners' relations}

Women evaluated their relations with partners during specific trimesters of their pregnancy. Neither primiparous nor multiparous women did report any statistically important changes in their relations with partners throughout three trimesters of their pregnancy. The distribution of self-assessed relations with the partner in specific trimesters was not statistically significant either. In most cases pregnant 


\begin{tabular}{|c|c|c|c|c|c|c|}
\hline \multirow{2}{*}{ Inventory } & \multirow{2}{*}{ Trimester } & \multicolumn{4}{|c|}{ Income per family member } & \multirow{2}{*}{ Kruskal-Wallis test } \\
\hline & & Up to 500 PLN & From 500 to 1000 PLN & From 1000 to 3000 PLN & Above 3000 PLN & \\
\hline \multirow{3}{*}{$\begin{array}{l}\text { STAI-x1 } \\
\text { State }\end{array}$} & 1 & $\begin{array}{c}41.5 \\
(28.8 ; 52.2)\end{array}$ & $\begin{array}{c}42.0 \\
(27.0 ; 54.0)\end{array}$ & $\begin{array}{c}38.5 \\
(28.0 ; 52.3)\end{array}$ & $\begin{array}{c}40.0 \\
(31.5 ; 54.5)\end{array}$ & NS $(p=0.89)$ \\
\hline & 2 & $\begin{array}{c}40.0 \\
(21.9 ; 51.0)\end{array}$ & $\begin{array}{c}38.0 \\
(24.0 ; 51.0)\end{array}$ & $\begin{array}{c}39.0 \\
(26.8 ; 43.3)\end{array}$ & $\begin{array}{c}39.0 \\
(30.5 ; 49.5)\end{array}$ & NS $(p=0.41)$ \\
\hline & 3 & $\begin{array}{c}39.5 \\
(30.8 ; 54.0)\end{array}$ & $\begin{array}{c}40.0 \\
(24.0 ; 54.0)\end{array}$ & $\begin{array}{c}41.0 \\
(28.5 ; 53.0)\end{array}$ & $\begin{array}{c}41.0 \\
(35.0 ; 56.5)\end{array}$ & NS $(p=0.80)$ \\
\hline \multirow{3}{*}{$\begin{array}{c}\text { STAI-x2 } \\
\text { Trait }\end{array}$} & 1 & $\begin{array}{c}47.0 \\
(36.0 ; 55.1)\end{array}$ & $\begin{array}{c}45.0 \\
(33.0 ; 56.0)\end{array}$ & $\begin{array}{c}44.5 \\
(28.058 .0)\end{array}$ & $\begin{array}{c}44.0 \\
(37.5 ; 56.0)\end{array}$ & NS $(p=0.92)$ \\
\hline & 2 & $\begin{array}{c}47.0 \\
(32.5 ; 53.0)\end{array}$ & $\begin{array}{c}43.0 \\
(30.0 ; 55.0)\end{array}$ & $\begin{array}{c}42.0 \\
(30.8 ; 56.0)\end{array}$ & $\begin{array}{c}44.0 \\
(36.0 ; 50.5)\end{array}$ & NS $(p=0.41)$ \\
\hline & 3 & $\begin{array}{c}47.0 \\
(34.3 ; 53.1)\end{array}$ & $\begin{array}{c}44.0 \\
(30.0 ; 56.0)\end{array}$ & $\begin{array}{c}44.0 \\
(31.8 ; 57.5)\end{array}$ & $\begin{array}{c}44.0 \\
(36.0 ; 56.0)\end{array}$ & NS $(p=0.75)$ \\
\hline
\end{tabular}

women claimed that their relations with their partners did not change.

The authors also tried to determine the correlation between women's assessment of relations with their partners and its impact on state and trait anxiety during specific trimesters of pregnancy in primiparous and multiparous women. The self assessed relations with the partner did not have any statistically significant impact on state and trait anxiety during first trimesters of pregnancy in primiparous and multiparous women.

The same dependency was evaluated for the second trimester. In the second trimester of pregnancy women's self assessment of relations with their partners had statistically significant impact on the increase of state anxiety $(p=0.04)$ in multiparous women, who reported impairment of their relations with the partner, and had statistically significant impact on the increase of the trait anxiety in primiparous $(p=0.02)$ and multiparous $(p=0.05)$ women, who reported deterioration of partnership.

A statistically significant difference between primiparous and multiparous women in terms of the trait anxiety $(p=0.01)$ was observed in pregnant women who declared that their relations with the partners did not change. In the third semester of pregnancy self-assessment of relations with partners did not have any significant impact on state or trait anxiety in both primiparas and multiparas.

Pregnant women were also asked in which trimester their sexual needs were higher. Statistical analysis showed that sexual needs were statistically different $(p<0.000001)$ throughout three trimesters of pregnancy. Most women (49.4\%) experienced higher sexual needs in the second trimester, some of them (44.0\%) - during first trimester and only $16.6 \%$ - during third trimester (Fig. 5).

Table 3 presents the results of the analysis of the correlation between state and trait anxiety and the frequency

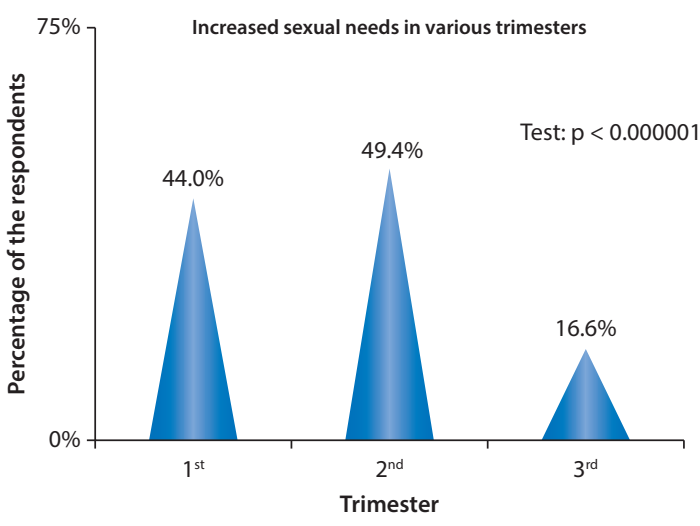

Figure 5. Higher sexual needs in specific trimesters as indicated by the subjects of the study

of sexual intercourse and women's perception of their own attractiveness and the frequency of sexual intercourse throughout three trimesters of pregnancy in primiparous and multiparous women. Kendal's tau coefficient showed the lack of analogy between STAI-x 1 and STAI-x 2 values and the sexual intercourse frequency as well as between the scale of attractiveness and sexual intercourse frequency.

\section{DISCUSSION}

There have been a number of psychosomatic research conducted to evaluate pregnant women's level of anxiety. One should note that the presence or lack of anxiety largely defines the quality of the individual's existence. High level of both state and trait anxiety significantly affects person's behavior and a way of thinking, making it more difficult to face the storms and difficulties of life.

Among surveyed women state anxiety changed significantly ( $p=0.001$ ) throughout the whole pregnancy. Statistically significant differences between specific trimesters were also observed. Half of the women (50.0\%) surveyed at 
Table 3. Kendal's tau coefficient together with the test for significant correlation of STAI inventory and the scale of women's attractiveness and the sexual intercourse frequency throughout three trimesters of pregnancy in primiparous and multiparous women

\begin{tabular}{|c|c|c|c|c|c|c|}
\hline \multirow{2}{*}{ Type of correlation } & \multicolumn{2}{|c|}{$1^{\text {st }}$ trimester } & \multicolumn{2}{|c|}{$2^{\text {nd }}$ trimester } & \multicolumn{2}{|c|}{$3^{\text {rd }}$ trimester } \\
\hline & Primiparas & Multiparas & Primiparas & Multiparas & Primiparas & Multiparas \\
\hline $\begin{array}{l}\text { STAI-x1 state with sexual } \\
\text { intercourse frequency }\end{array}$ & $\begin{array}{c}\tau=0.03 \\
N S(p=0.68)\end{array}$ & $\begin{array}{c}\tau=0.03 \\
N S(p=0.70)\end{array}$ & $\begin{array}{c}\tau=-0.08 \\
N S(p=0.31)\end{array}$ & $\begin{array}{c}\tau=-0.01 \\
N S(p=0.88)\end{array}$ & $\begin{array}{c}\tau=-0.02 \\
N S(p=0.83)\end{array}$ & $\begin{array}{c}\tau=-0.06 \\
\text { NS }(p=0.48)\end{array}$ \\
\hline $\begin{array}{l}\text { STAI-x2 state with sexual } \\
\text { intercourse frequency }\end{array}$ & $\begin{array}{c}\tau=0.07 \\
N S(p=0.35)\end{array}$ & $\begin{array}{c}\tau=-0.12 \\
N S(p=0.15)\end{array}$ & $\begin{array}{c}\tau=0.02 \\
N S(p=0.75)\end{array}$ & $\begin{aligned} \tau & =0.06 \\
N S(p & =0.75)\end{aligned}$ & $\begin{array}{c}\tau=-0.05 \\
N S(p=0.55)\end{array}$ & $\begin{array}{c}\tau=-0.13 \\
N S(p=0.15)\end{array}$ \\
\hline $\begin{array}{l}\text { Attractiveness scale with } \\
\text { the sexual intercourse } \\
\text { frequency }\end{array}$ & $\begin{array}{c}\tau=0.05 \\
\text { NS }(p=0.52)\end{array}$ & $\begin{array}{c}\tau=0.01 \\
\text { NS }(p=0.91)\end{array}$ & $\begin{array}{c}\tau=-0.02 \\
N S(p=0.82)\end{array}$ & $\begin{array}{c}\tau=-0.08 \\
N S(p=0.36)\end{array}$ & $\begin{array}{c}\tau=-0.01 \\
N S(p=0.89)\end{array}$ & $\begin{array}{c}\tau=-0.13 \\
N S(p=0.14)\end{array}$ \\
\hline
\end{tabular}

the beginning of their pregnancy reported increased anxiety level and $10.8 \%$ of surveyed women reported high anxiety level. In the second trimester of pregnancy state anxiety decreased and most women (60.7\%) experienced low anxiety level. In the third semester the numbers of subjects with high and low anxiety level were pretty similar. Only $2.4 \%$ of the subjects suffered from high anxiety.

Presented own research confirmed the observations by other experts in the field $[3,7,8]$. At the beginning of the pregnancy anxiety is the reflection of a new life situation. Pregnancy is the state of developmental crisis, which is common in all people undergoing changes in their lives. According to this concept human's personality is shaped by the strong psychological stressor, which initially lowers psychological function but eventually leads to its effective activation which increases the efficiency [3].

The increased anxiety level at this time is the effect of women's social situation. It applies mainly to informing family and friends about pregnancy. Informing the partner, his reaction and his parents' reaction and women's own feelings about being a mother are particularly important.

Research conducted by Heron et at. [9] confirm the correlation between mother's emotional state and the course of her pregnancy, with stress level and anxiety being important factors.

Hormonal changes can aggregate the symptoms of anxiety [10]. Moreover, pregnancy is the time of increased susceptibility to emotional liability [11]. During second semester women get used to their new roles and their partners and families'acceptance, which helps to strengthen positive emotions about having a child [12].

A number of authors have already investigated the emotions experienced by pregnant women. Oppenheim [13] noticed a visible improvement of emotional state in the second trimester. Pregnant women presented more positive emotions as compared to other trimesters.

In the third trimester symptoms related to childbirth, its course, possible complications and dangers threatening the women and the child, intensive pain and new family situation may increase [14].

Trait anxiety is an acquired behavioral predisposition to perceive relatively non-dangerous situations as threatening, which triggers anxiety reactions. Trait anxiety is then an established personality trait [9]. In this research it changed statistically $(p=0.07)$ throughout specific trimesters of pregnancy. Statistically significant differences between trimesters were also observed: Between the first and the second $-p=0.03$ and between the second and the third $-p=0.01$.

Trait anxiety, a relatively constant feature, affects also attitude towards childbirth. Pregnancy is a very special time, when women change the perception of themselves - their bodies. The amount and type of support and the need for high self-esteem also changes. And finally, woman's social role is about to change, she will become a mother - it's particularly important for women in their first pregnancy. This aspect seems most important for justifying the changeability of trait anxiety throughout the pregnancy, particularly in primiparous women [3]. Research prove that the first pregnancy is such an important moment in women's life that it changes her personality and the way she perceives herself.

Quoted results show that not only primiparas suffer from the fear of childbirth. Multiparas are afraid of the delivery as well. Traumatic memory of the childbirth turns out to be even stronger that the fear of unknown experienced by primiparas. Similar results were achieved by Bielawska-Batorowicz [3] and these observations are also confirmed by already classic research on the psychological aspects of pregnancy by Shereshefsky and Yarrow [15]. Wenzel et al. [16] and Wiktor et al. [8] had a different opinion and claimed that a higher anxiety level was the result of a number of children. However, a statistically higher state anxiety was observed in primiparous women than in women in their second or higher pregnancy.

Primiparas and multiparas did not differ in trait anxiety. Statistically significant changes throughout three trimesters 
of pregnancy were observed only for primiparas $(p=0.006)$. In each trimester and in both groups an increased trait anxiety prevailed. It was probably pregnancy-related. When comparing the distribution of state anxiety and trait anxiety a reduction in state anxiety, particularly in the second trimester of pregnancy in primiparous women, was observed, which may suggest that pregnant women pay greater attention to their needs, their well-being and they get more support from their partners and family. Higher state anxiety was observed in pregnant women with higher trait anxiety. These results are in line with results of other researchers (Rutkowska et al. [7], Podolska et al. [17], Bączyk et al. [14]). In the research group trait anxiety was higher among multiparous women. As Zar et al. [18] observed trait anxiety that occurs after the delivery may be a deeply rooted tendency to reacting with fear to all delivery-related issues such as perinatal procedures or child's condition. While state anxiety is clearly linked to the knowledge on delivery and previous obstetric history. This theory was not confirmed by the research conducted by Bączyk et at. [14] who claimed that previous deliveries does not lower or increase anxiety and each childbirth is a new and unique experience for the woman.

Lower anxiety level in the second trimester contributed to the increased sexual activity. This is confirmed by the research conducted by Bielawska-Batorowicz [3], who also observed the increase in the sexual interest and needs in the second trimester of pregnancy. Figueira et al. [19] found that anxiety is one of the main factors responsible for sexual dysfunctions.

In the research group no statistically significant relationship between subjects' age, financial status, education and the level of state and trait anxiety was observed.

Rymaszewska [20] claim that mood disorder risk factors during the perinatal period are: genetic disposition, social and economic factors and personality features. Literature data confirm that perinatal period is the time of increased risk for the development and intensification of anxiety and depressive disorders, which may adversely affect the course of pregnancy, delivery and puerperium [16, 21, 22].

The conducted research showed statistically important $(p=0.02)$ impact of everyday stress on the state anxiety in the first trimester of pregnancy. Stress did not affect trait anxiety in any trimester. In this respect the results of conducted study are in line with the results of other authors [8,20].

Proper sexual relations must be build through proper communication between the partners. They need to learn to talk with each other throughout the whole process of building partner and sexual relations. Research show that $23.5 \%$ of women do not discuss their sexual life with their partners [23].

In relationships where partners care about each other and effectively communicate their sexual needs the proba- bility of sexual disorders is relatively lower [24]. Research conducted by Gonzales et al. [25] showed that educated women who were satisfied with their relations with the partner more deeply and easily experienced sexual desire.

Satisfaction with their relationships affected the level of lust. Women who felt more fulfilled in their relationships noted lower decrease in sexual desire and sexual intercourse frequency [4].

As Kingsberg suggests [26] on the basis of her research, regardless of the duration of the relationship and the relations between the partners, its quality should be strengthened by emotional closeness, independency, the ability to overcome everyday stress and most of all, by positive perception of oneself and one's personal relations with the partner.

Research conducted by Gokyildiz et al. [27] showed that women who claimed to have good relations with their partners by showing and receiving friendliness and affection more often reached sexual satisfaction.

Anxiety level during pregnancy significantly affected the quality of sexual activity. Lower anxiety level in the second trimester contributed to the increased sexual activity.

\section{Acknowledgements}

None.

\section{Author disclosure statement}

No competing financial interests exist. The authors report no financial, personal, political, intellectual or religious conflicts of interest. The authors alone are responsible for the content and writing of the paper.

\section{REFERENCES}

1. Laphimon MA. Glossary of Term In Gender and Sexuality. Seul: The Rockefeller Foundation. Mahidol University Thailand 2002.

2. Lew-Starowicz Z. Psychospołeczne podstawy seksualności. In: Lew-Starowicz Z, Skrzypulec V. ed. Podstawy seksuologii. Wydawnictwo Lekarskie PZWL, Warszawa 2010: 25-26.

3. Bielawska-Batorowicz E. Psychologiczne aspekty prokreacji. Wydawnictwo Naukowe Śląsk, Katowice 2006

4. DeJudicibus MA, McCabe MP. Psychological factors and the sexuality of pregnant and postpartum women. J Sex Res. 2002; 39(2): 94-103, doi: 10.1080/00224490209552128, indexed in Pubmed: 12476241.

5. Raphael L. Psychological processes of childbearing. Chapman and Hall, London 1991.

6. Wrześniewski K, Sosnowski T, Jaworowska A. Inwentarz Stanu i Cechy Lęku STAI. Polska adaptacja STAI. Pracownia Testów Psychologicznych, Warszawa 2006.

7. Rutkowska A, Rolińska A, Kwaśniewski W, et al. Lęk - jako stan i jako cecha u kobiet w ciąży prawidłowej i wysokiego ryzyka. Curr Probl Psychiatr. 2011; 12: 56-59.

8. Wiktor $\mathrm{H}$, Lewicka $\mathrm{M}$, Humeniuk $\mathrm{E}$, et al. Ocena poziomu lęku u kobiet w połogu. Ann Acad Med Stetin. 2009; 55: 66-69.

9. Heron J, O'Connor TG, Evans J, et al. ALSPAC Study Team. The course of anxiety and depression through pregnancy and the postpartum in a community sample. J Affect Disord. 2004; 80(1): 65-73, doi: 10.1016/j. jad.2003.08.004, indexed in Pubmed: 15094259. 
10. Williams KE, Casper RC. Reproduction and its psychopathology. In: Casper RC. ed. Womens Health: Hormones, emotions and behavior. Cambridge University Press, Cambridge 1998: 14-35.

11. Hipwell AE, Reynolds S, Crick EP. Cognitive vulnerability to postnatal depressive symptomatology. J Reprod Infant Psycho. 2004; 22(3): 211-227, doi: 10.1080/02646830410001723797.

12. Kroelinger CD, Oths KS. Partner support and pregnancy wantedness. Birth. 2000; 27(2): 112-119, doi: 10.1046/j.1523-536x.2000.00112.x, indexed in Pubmed: 11251489.

13. Oppenheim GB. Psychological disorders in pregnancy. In: Priest RG. ed. Psychological disorders in obstetrics and gynecology. Butterworth, London 1995: 93-146.

14. Bączyk G, Cybulska V, Koźlak V, et al. Poziom lęku przedporodowego u kobiet w ciąży. Probl Hig Epidemiol. 2011; 92: 762-765.

15. Shereshefsky PM, Yarrow LJ. Psychological aspects of a first pregnancy and early postnatal adaptation. Raven Press Publishers, New York 1973.

16. Wenzel A, Haugen EN, Jackson LC, et al. Prevalence of generalized anxiety at eight weeks postpartum. Arch Womens Ment Health. 2003; 6(1): 43-49, doi: 10.1007/s00737-002-0154-2, indexed in Pubmed: 12715263.

17. Podolska M, Majewska A. Lęk jako stan i jako cecha w grupie kobiet, u których zakończono ciążę za pomocą cięcia cesarskiego. Kliniczna Perinatologia i Ginekologia. 2007; 4: 60-63.

18. Zar M, Wijma K, Wijma B. Pre- and Postpartum Fear of Childbirth in Nulliparous and Parous Women. Scand J Behav Ther. 2001; 30(2): 75-84, doi: 10.1080/02845710152507418.

19. Figueira I, Possidente E, Marques C, et al. Sexual dysfunction: a neglected complication of panic disorder and social phobia. Arch Sex Behav. 2001; 30(4): 369-377, indexed in Pubmed: 11446198.
20. Rymaszewska J, Dolna $M$, Gryboś $M$, et al. [Mental disorders during pregnancy and postpartum period - epidemiology, etiology, classification and treatment]. Ginekol Pol. 2005; 76(4): 322-330, indexed in Pubmed: 16013188.

21. Dayan J, Yoshida K. [Psychological and pharmacological treatments of mood and anxiety disorders during pregnancy and postpartum. Review and synthesis]. J Gynecol Obstet Biol Reprod (Paris). 2007; 36(6): 530-548, doi: 10.1016/j.jgyn.2007.06.004, indexed in Pubmed: 17616265.

22. Lonstein JS. Regulation of anxiety during the postpartum period. Front Neuroendocrinol. 2007; 28(2-3): 115-141, doi: 10.1016/j.yfrne.2007.05.002, indexed in Pubmed: 17604088.

23. Wróbel B. Wyniki badania wybranych cech seksualności kobiet w związku małżeńskim. Ginekol Pol. 2008; 79(2): 99-107, indexed in Pubmed: 18510088.

24. Laumann EO, Nicolosi A, Glasser DB, et al. GSSAB Investigators' Group. Sexual problems among women and men aged $40-80$ y: prevalence and correlates identified in the Global Study of Sexual Attitudes and Behaviors. Int J Impot Res. 2005; 17(1):39-57, doi: 10.1038/sj.ijir.3901250, indexed in Pubmed: 15215881.

25. González M, Viáfara G, Caba F, et al. Libido and orgasm in middle-aged woman. Maturitas. 2006; 53(1): 1-10, doi: 10.1016/j.maturitas.2004.07.003, indexed in Pubmed: 16213679.

26. Kingsberg SA. The impact of aging on sexual function in women and their partners. Arch Sex Behav. 2002; 31(5): 431-437, indexed in Pubmed: 12238611.

27. Gökyildiz S, Beji NK. The effects of pregnancy on sexual life. J Sex Marital Ther. 2005; 31(3): 201-215, doi: 10.1080/00926230590513410, indexed in Pubmed: 16020139. 